\title{
DeteCtion OF COPROANTIGEN IN EARLY TRICHINELLOSIS
}

\author{
BOULOS L.M.*, IBRAHIM I.R*, NEGM A.Y.* \& ALY S.M.*
}

\section{Summary :}

Trichinellosis has become undoubtedly worldwide in distribution. Its diagnosis relies largely on the serodiagnostic procedures which are of great value but unfortunately miss the enteric phase. This could be a serious diagnostic problem in the absence of corresponding epidemiological data and typical symptoms and signs of the disease. In this study the possibility of coproantigen detection, as an early diagnostic aid in trichinellosis, was investigated in mice experimentally infected with Trichinella spiralis.

A modified double sandwich ELISA was developed using polyclonal antibodies raised in rabbits and guinea pigs against larval somatic antigens. The first detection of coproantigen was as early as the first day post infection, gradually increasing to reach its peak on the seventh day and then decreasing to disappear completely on the third week post infection. Another test, the coagglutination test ( $\mathrm{Co}-\mathrm{A})$ was used, and this test confirmed the previous results. The finding of this study suggest that the coproantigen detection could be exploited to confirm ongoing early Trichinella spiralis infection. This fast and easy to use diagnostic method should improve the early infection in human.

KEY WORDS : T. spiralis, coproantigen, ElISA, Co-A.

T Trichinellosis has been recognized as an important public health problem (Kim, 1993). However, in Egypt, trichinellosis has never been given much importance as the majority of inhabitants do not eat pork (Rifaat et al., 1969), yet the possibility of infection remains as evidenced by the reports of human cases (Boctor et al., 1986). This may be partially due to ingestion of pork or its use in adulterating processed beef in order to reduce its costs (El-Temsahi, 1991). Human cases infected with Trichinella spiralis may be misdiagnosed as enteric bacterial infection can present similar symptoms during the intestinal phase of clinical trichinellosis (Beaver et al., 1984).The early intestinal phase requires a confirmatory test to assure an accurate diagnosis, as convenient rapid methods of diagnosis at this stage are not usually available. The development of immunologic or molecular methods to detect helminth stages or their products has the poten-

\footnotetext{
* Parasitology Department, Faculty of Medicine, Alexandria University, Egypt. Tel.: 035451360 - Fax: 035854508.

e-mail:smhz@intouch.com
}

tial to provide highly specific and sensitive diagnosis of gastro-intestinal tract infections (Fraser \& Craig, 1997).

Nowadays, coproantigen detection has proved to be useful in the diagnosis of many parasitic infections (Morishima et al., 1999). However its use in the diagnosis of T. spiralis infection has not yet been assessed. Therefore, the aim of the present work was to study the possibility of early diagnosis of $T$. spiralis infection by detection of coproantigen in stool using both the modified double sandwich ELISA test and the coagglutination test (Co-A test) which is a novel immunological method (Karki \& Parija, 1999).

\section{MATERIAL AND METHODS}

\section{PARASITE}

The isolate of T. spiralis (ISS100) used in this study was obtained by enzymatic digestion of infected pork obtained from the main slaughter house in Alexandria. The isolate was maintained in our laboratory by serial passages in Swiss strain albino mice.

\section{EXPERIMENTAL MICE AND ANTIGEN PREPARATION}

Twenty mice infected orally with 300 larvae each were used as a source for larval antigen preparation (Lee et al., 1982). The protein content was assessed by the Biorad method (Norbert \& Tietz, 1987).

Another 20 mice were used for detection of coproantigen. They were each infected with 300 larvae/mouse.

\section{PREPARATION OF HYPERIMMUNE SERA}

Hyperimmune sera raised against crude larval antigen of T. spiralis were prepared in both rabbits and guinea pigs according to Takahashi et al., 1989. The protein content was assessed by the Biorad method (Norbert \& Teitz, 1987) and the antibodies were tested against T. spiralis antigen by counterimmunoelectrophoresis (Vanoss et al., 1973). 


\section{DETECTION OF COPROANTIGEN OF T. SPIRALIS}

Stools from mice infected with $T$. spiralis were collected at one, three, five, nine, 14, 21 and 28 days post-infection (PI). At the end of the experiment, all mice were sacrificed and the diaphragm was examined for T. spiralis muscle larvae.

Stool analysis using saline smear was done to all specimens to exclude the presence of other parasites. Stool samples were then preserved in PBS and stored at - 35 C (Chapman et al., 1990).

\section{PREPARATION OF FAECAL SUPERNATANT FRACTIONS} (Allan et al., 1992)

Stool samples were prepared by mixing faecal material with an equal weight-volume ratio of $0.15 \mathrm{M}$ PBS containing $0.3 \%$ Tween 20 (Sigma). Each sample was then shaken vigorously to form a slurry and centrifuged at $2,000 \mathrm{~g}$ for 30 minutes at room temperature. The supernatant was then collected and added to an equal volume of heat-inactivated foetal calf serum to be ready for detection of $T$. spiralis coproantigen by both ELISA test and Co-agglutination test.

\section{COPROANTIGEN ENZYME LINKED IMMUNOSORBENT ASSAY (ELISA)}

Modified double sandwich ELISA (Ungar, 1990) was done to detect $T$. spiralis antigen in all stool samples. The optical density (OD) values were read by an
ELISA reader at a wave length of $492 \mathrm{~nm}$. T. spiralis antigen was introduced as a positive control whereas stools of uninfected mice were used as a negative control. The cut off value was adjusted to be twice the mean OD value of the negative control. In addition, the means and standard deviations were calculated according to Pipkin (1984).

\section{CO-AGGLUTINATION TEST}

Co-A test was done for detection of T. spiralis antigen in stools according to Karki \& Parija, 1999. The principle of the test depends on the combination of the specific parasite antigens present in the stool specimens and SAPA cells (Sigma No 9151) resulting in viable clumping of cells in the positive reaction. The degree of agglutination was assessed by the diameter of the clumps and clearance of background (Boulos et al., 1999). Positive and negative controls were used as previously mentioned with the ELISA test.

\section{RESULTS}

\section{ELISA TEST}

The ELISA test gave positive reaction from the first day PI. The titre increased gradually to reach its peak on the $7^{\text {th }}$ day PI, after which it started to

decrease gradually but was still positive at the end of

\section{OD $492 \mathrm{~nm}$}

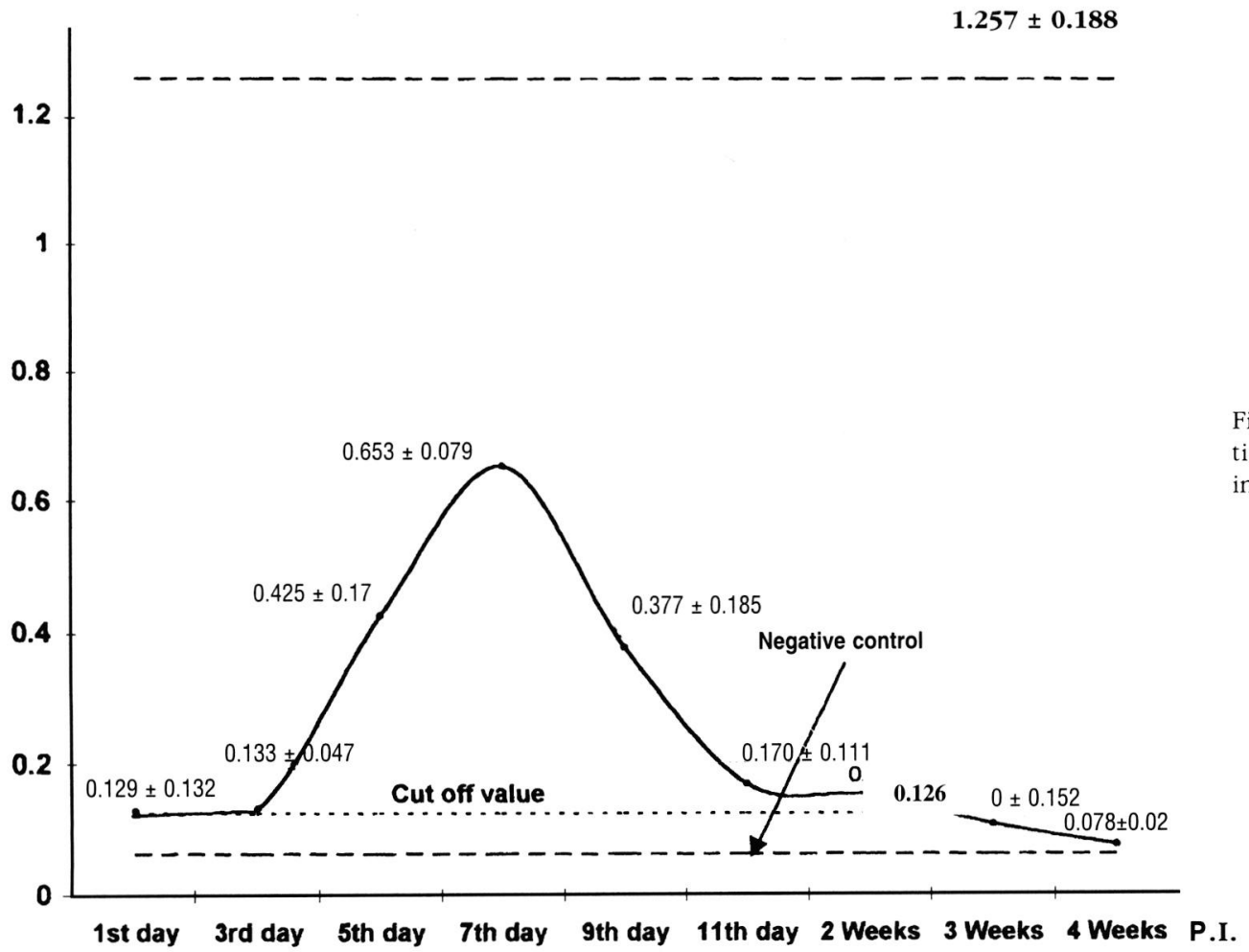

Fig. 1. - Detection of coproantigen during the time-course infection using the ELISA test. 
Fig. 2. - Detection of coproantigen during the time-course infection using the CoAgglutination test.

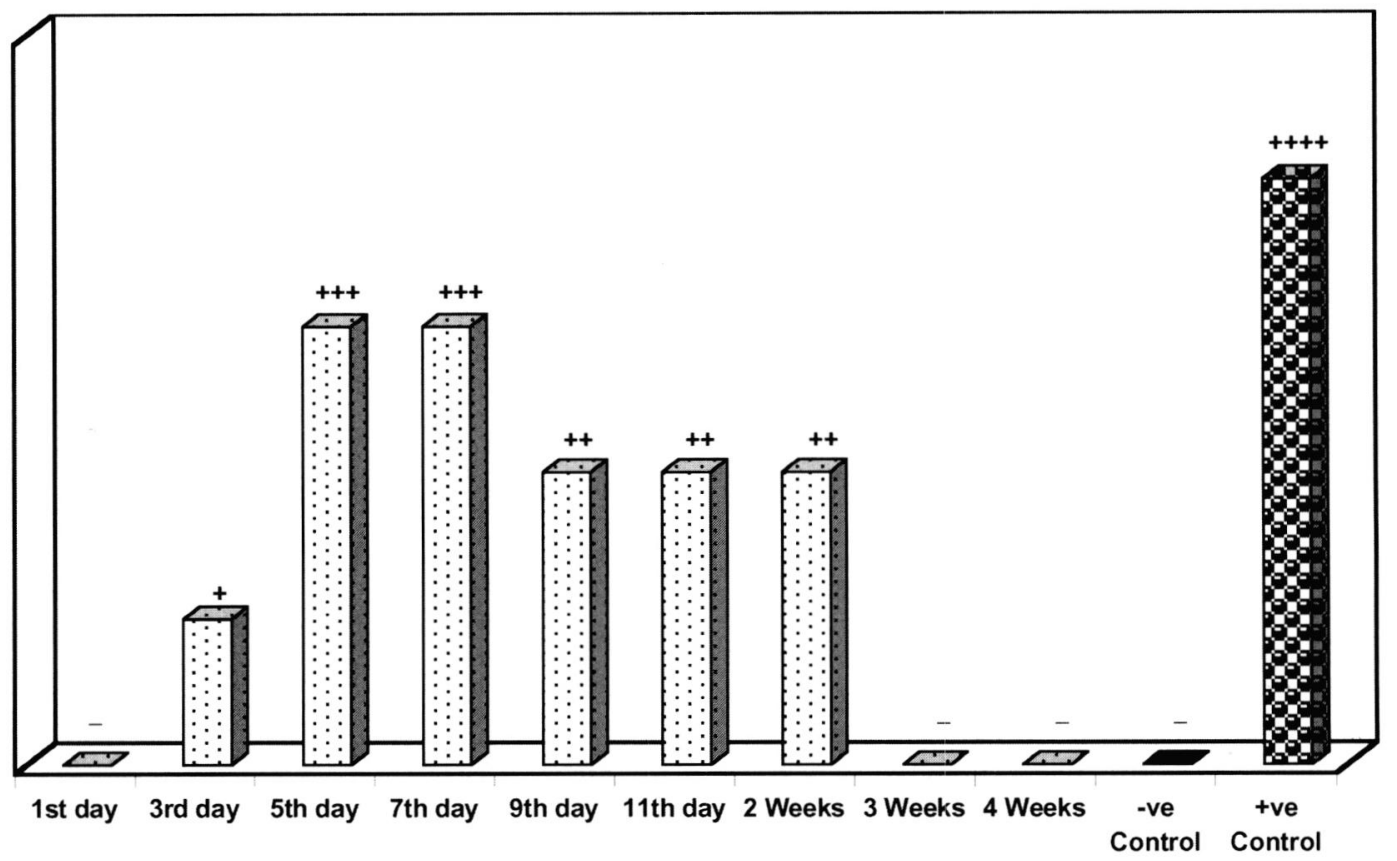

the $2^{\text {nd }}$ week. On the third and fourth weeks PI negative results were detected (Fig. 1).

\section{CO-A TEST}

Agglutination reaction was detected starting from the $3^{\text {rd }}$ day PI. Maximum agglutination was reached on the $5^{\text {th }}$ day PI. The reaction decreased gradually till the end of second week after which no agglutination was detected i.e. on $3^{\text {rd }}$ and $4^{\text {th }}$ week negative reaction was observed (Figs 2, 3).

\section{DISCUSSION}

T The Coproantigen detection assay has the advantage of diagnosis during the prepatent period of many infectious diseases (Allan et al., 1990). This was exploited in the present study and its validity was investigated using ELISA and CoA test.

The ELISA test in this work gave positive reaction from the third day PI. The peak was reached on the $7^{\text {th }}$ day and remained positive for two weeks. The detected antigen could be associated with the turnover of the parasite surface or it may be an excretory / secretory product. The variation in antigen level at different intervals is probably related to the parasite development (Nonaka et al., 1996). Accordingly, the presence of antigen from the first day is probably due to the direct passage of some larvae in the stools. In addition the moulting process of first stage larvae is known to vary between 8-30 hrs PI in males and from 1131 hrs PI in females (Kozek, 1971) after which adult
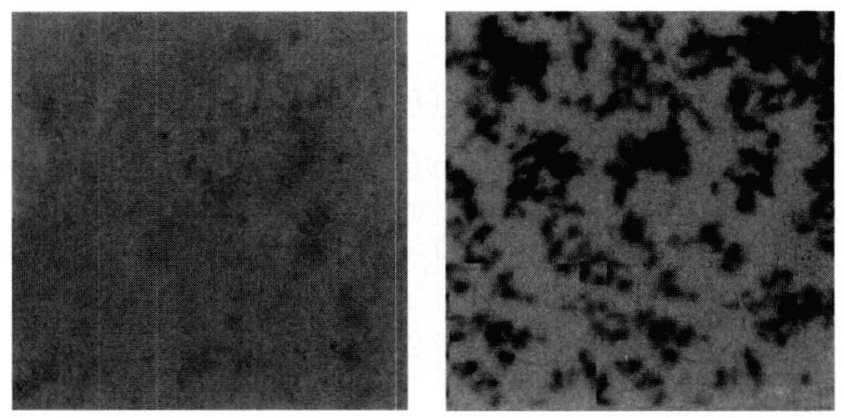

Positive reaction Indicated by absence of
clumping (X 100)

Negative reaction
Showing obvious clumping of the cells (X 100)

Fig. 3. - Co-Agglutination test showing the difference between the negative and positive reaction.

worms develop. This takes place on the third day and coincides with the beginning of enteritis. At this stage new granules are formed within the stichocytes leading to more antigen secretion. Some of these stichocytes continue to harbour the antigen till the $6^{\text {th }}$ day PI. (Capo et al., 1986), and may explain the gradual increase of antigen level detected in the present study. The peak reached on the $7^{\text {th }}$ day PI possibly coincides with parasite expulsion, a finding which was also detected in Strongyloides ratti (Nageswaran et al., 1994). During the $3^{\text {rd }}$ and $4^{\text {th }}$ weeks PI no antigen was detected in the stool in the present study. This is probably because, at this stage all worms have already been expelled and the larvae have reached the tissues. It was also noticed that the CoA test confirmed the results of ELISA except that it gave negative reaction on the first day. This could be attributed to the higher 
sensitivity and accuracy of ELISA test since it is read by spectrophotometry. However, although ELISA is more accurate than $\mathrm{CoA}$ test, the $\mathrm{CoA}$ test appeared easy to use, fast and does not require any technical skills.

Coproantigen detection has certain advantages over conventional serological assays as T. spiralis antigens is not detectable in serum by ELISA before a month (Rodriguez-Osorio, 1999). It is a simple method that can be helpful during the intestinal phase without the necessity of special equipment. The method can also be applied in surveys and in Trichinella outbreaks. In addition coproantigens rapidly disappear from faeces after treatment and is a good marker of active infection.

\section{REFERENCES}

AlKarmi T.O. \& Faubert G.M. Studies on antigenic differences between the larvae of Trichinella pseudospiralis and Trichinella spiralis by gel diffusion and immunoelectrophoretic techniques. In: Kim C.W., ed. Trichinellosis. New York, University Press of New York, 1985, 140-145.

Allan J.C., Avila G., Noval J.G., Flisser A. \& Craig P.S. Immunodiagnosis of taeniasis by coproantigen detection. Parasitology, 1990, 101, 473-477.

allan J.C., Craig P.S., Garcia noval J., Mencos F., Liu D., Wang Y., Wen H., Zhou P., Stringer R., Rogan M. et al. Coproantigen detection for immunodiagnosis of echinococcosis and taeniasis in dogs and humans. Parasitology, 1992, 104, 347-356.

Beaver P.C., Jung R.C. \& Cupp E.W. Aphasmid Nematodes (Adenophorea). In: Clinical Parasitology, $9^{\text {th }}$ ed. Philadelphia, Lea and Febiger, 1984, 18, 231-249.

Boctor F.N., Girgis N. \& FARID Z. Trichinosis meningioencephalitis. A case report ELISA serodiagnosis and treatment. Journal of Egyptian Society of Parasitology, 1986, 16 (2), 727-732.

Boulos L.M., El Mansoury S.T., Sadaka H.A., Zin El Deen S., KALIFA A.M., \& SAID D. Evaluation of the Co-Agglutination test in diagnosis of hydatid disease. $4^{\text {th }}$ Annual Summer meeting of the Egypt Society of Tropical Medicine and Parasitology, 1999, 12.

Capo V., Silberstein D. \& Despommier D.D. Immunocytolocalization of two protection-inducing antigens of $T$. spiralis during its enteral phase in immune and nonimmune mice. Journal of Parasitology, 1986, 72, 931-938.

EL-TemSAH M.M. Evaluation of enzyme linked immunosorbent assay and counter current immunoelectrophoresis in the diagnosis of experimental trichinosis. Thesis, M. D. Alexandria, Faculty of Medicine, 1991, 43.

Fraser A. \& Craig P.S. Detection of gastrointestinal helminth infections using coproantigen and molecular diagnostic approaches. Journal of Helmintbology, 1997, 71, 103-107.

KARKI B.M.S. \& PARIJA C. Co-agglutination test for the detection of circulating antigen in amoebic liver abcess. American Journal of Tropical, Medicine and Hygiene, 1999, 60 (3), 498-501.
KIM C.W. A decade of progress in trichinellosis. In: Proceedings of the $8^{\text {th }}$ International Conference on Trichinellosis, 1993, 35-45.

KOZAK W. The moulting pattern in Trichinella spiralis. 1. A light microscope study. The Journal of Parasitology, 1971, 57 (5), $1015-1028$

LEe T.D.G., GREnCIS R.R. \& Wakelin D. Specific cross-immunity between Trichinella spiralis and Trichuris muris: immunization with heterologous immune mesentery lymph node cells. Parasitology, 1982, 84, 381-389.

Morishima Y.T., Snkada H., Nonaka N., Oku Y. \& Kamiya M. Evaluation of coproantigen diagnosis for natural Echinococcus multilocularis infection in red foxes. Japanese Journal of Veterinary Research, 1999, 46 (4), 185-189.

Nageswaran C., Craiy P.S. \& Devaney E. Coproantigen detection in rats experimental infected with Strongyloides ratti. Parasitology, 1994, 180, 335-342.

Nonaka N., Iida M., Yagi K., Ito T., OOI H.K., Oku Y \& KamiYA M. Time course of corproantigen excretion in Echinococcus multilocularis infections in foxes and an alternative definitive host, golden hamsters. International Journal of Parasitology, 1996; 26 (11), 1271-1278.

NORBERT W. \& TIETz X. Fundamentals of clinical chemistry. Third edition WB. Saunders Company, 1987, 315.

PIPKIN F.B. Medical statistics made easy. Edinburg, London, Melbourne. New York: Churchill Livingstone, 1984, 24.

RifaAt M.A., Mahdi A.H., \& ARAFA M.S. Further evidence that Egypt is Trichinella free. Journal of Egyptian Public Health Association, 1969, 44, 193-198.

Rodriguez-Osorio M. Human trichinellosis in Southern Spain: serologic and epidemiologic study. American Journal of Tropical Medicine and Hygiene, 1999, 61 (5), 834-837.

Takahashi Y., Uno T., Mizuno A., Yamada S., Nakahoma M., \& ARAKI T. T. spiralis: antigenic substances associated with the alimentary tract. Experimental Parasitology, 1989, 58, 414-422.

UNGAR B.L.P. Enzyme-linked immunosorbent assay for detection of Cryptosporidium antigen in faecal specimens. Journal of Clinical Microbiology, 1990, 28, 2491-2495.

Vanoss C.J., Bigazzi P.E., Barron A., Rabin B., Bartholmew V. \& WICHER K. Precipitation reaction; counterimmunoelectrophoresis. In: Rose N.R., Bigazzi P.E., eds. Methods in immunodiagnosis. New York, London, Sydney, Toronto. John Wiley \& Sons Inc, 1973, 1-30. 